\section{Closure of a gastrocutaneous fistula by a tulip-bundle technique}

A 79-year-old woman developed a gastrocutaneous fistula after removal of a $20-\mathrm{Fr}$ percutaneous endoscopic gastrostomy (PEG) tube. During endoscopy, the gastric orifice was identified ( $\bullet$ Fig. 1 ) and an unsuccessful attempt was made to close the fistula using endoclips. Therefore, we used a tulip-bundle technique [1], which is a variation of the combined endoloop and endoclip method that was originally described for the closure of large iatrogenic perforations $[2,3]$.

A two-channel endoscope (GIF-2T160; Olympus, Tokyo, Japan) was used with simultaneous insertion of the endoloop applicator device (HX-20; Olympus) and the endoclip rotary delivery system (HX-110UR; Olympus). The 30-mm endoloop snare (MAJ-254; Olympus) was anchored to the normal mucosa within $5 \mathrm{~mm}$ of the edge of the defect using seven endoclips (Ez-Clip-XH-610-090L; Olympus; Fig. 2). Finally, the endoloop was tightened to close the edges of the opening ( Fig. 3). At the end of the procedure, there was no air leakage from the cutaneous orifice and a follow-up endoscopy performed 1 month later showed complete closure of the fistula.

To our knowledge, this is the first report of the endoscopic closure of a gastrocutaneous fistula using the tulip-bundle technique. Unlike in the original method where the endoloop snare is anchored by two endoclips [2], with the tulip-bundle modification the endoloop snare is anchored circumferentially around the gastric defect by multiple endoclips. Care must be taken to avoid tangential placement of the endoclips. Correct deployment of the endoclips is made easier if the fistula orifice is forward-facing, as is the case for a PEG orifice, which is usually located on the anterior wall of the gastric corpus. Placement of the endoclips should start at the distal edge (the edge furthest from the mouth) and continue around both sides of the defect. When the cir- cumferential placement of the endoclips is complete, the endoloop snare should be tightened gently to avoid the endoclips becoming detached.

In conclusion, this case shows that the endoscopic tulip-bundle technique is an excellent nonsurgical option for closure of a chronic gastrocutaneous fistula, which may be particularly useful in elderly patients at high risk for surgery.

\section{Endoscopy_UCTN_Code_TTT_1AO_2AI}

Competing interests: None

F. Perri, M. Gentile, D. Scimeca,

F. Terracciano, A. Merla, F. Spirito,

\section{A. Andriulli}

Endoscopic Unit, IRCCS "Casa Sollievo della Sofferenza” Hospital, San Giovanni Rotondo, Italy

\section{References}

1 Mocciaro F, Curcio G, Tarantino I et al. Tulip bundle technique and fibrin glue injection: unusual treatment of colonic perforation. World J Gastroenterol 2011; 17: 1088-1090

2 Matsuda T, Fujii T, Emura F. Complete closure of a large defect after EMR of a lateral spreading colorectal tumor when using a two-channel colonoscope. Gastrointest Endosc 2004; 60: 836-838

3 Nakagawa $Y$, Nagai T, Soma $W$ et al. Endoscopic closure of a large ERCP-related lateral duodenal perforation by using endoloops and endoclips. Gastrointest Endosc 2010; 72: $216-217$

\section{Bibliography}

DOI $10.1055 / \mathrm{s}-0030-1256957$

Endoscopy 2011; 43: E419

(c) Georg Thieme Verlag KG Stuttgart · New York . ISSN 0013-726X

\section{Corresponding author \\ F. Perri, MD, PhD}

Endoscopic Unit

IRCCS “Casa Sollievo della Sofferenza" Hospital 71013 San Giovanni Rotondo

Italy

Fax: +39-0882-410989

fp.perri@libero.it

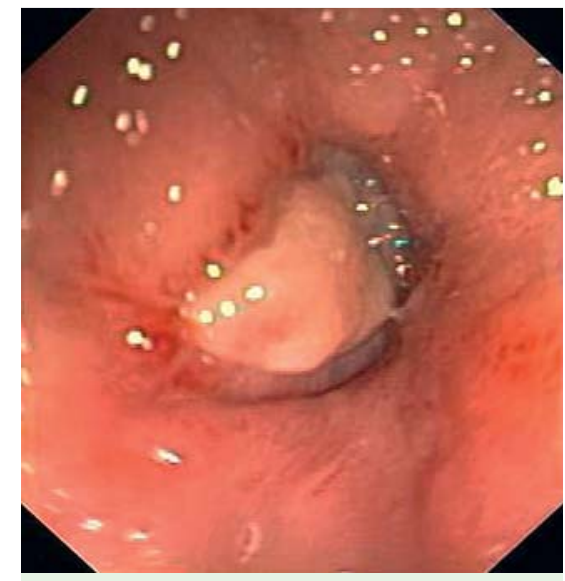

Fig. 1 Endoscopic appearance of the gastric opening of the gastrocutaneous fistula.

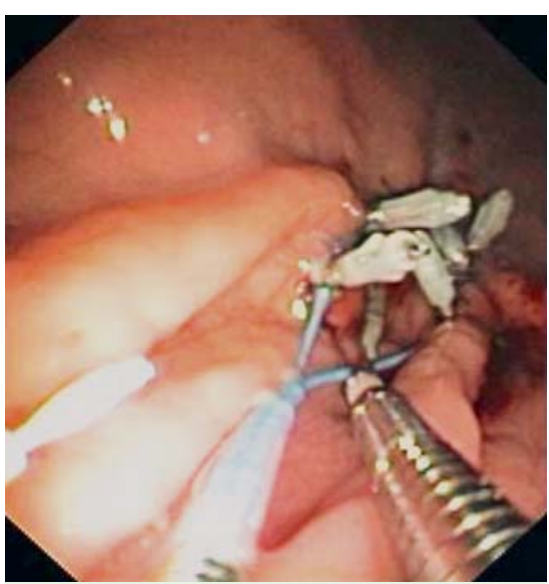

Fig. 2 The partially anchored endoloop snare is shown with the sixth endoclip about to be placed at the proximal edge of the fistula.

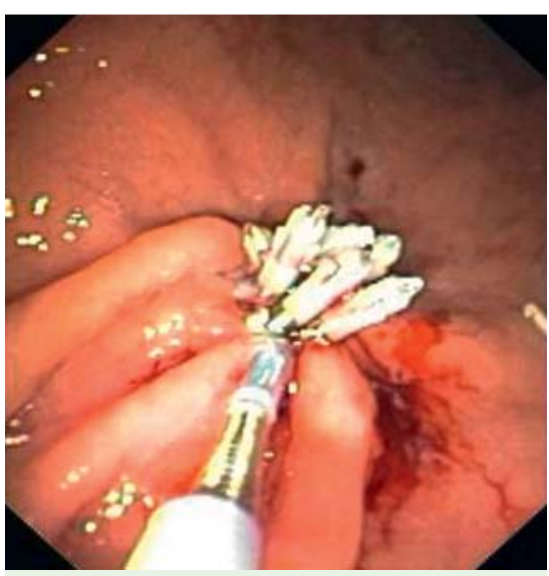

Fig. 3 Appearance following tightening of the endoloop snare showing that complete closure of the gastric opening of the fistula has been achieved with the combined endoloop and endoclip suture. 